\title{
High antistreptolysin 0 titer is associated with coronary artery lesions in patients with Kawasaki disease
}

\author{
Dong Eun Min, MD', Do Hee Kim, MD', Mi Young Han, MD', Sung Ho Cha, MD', Kyung Lim Yoon, MD, PhD² \\ ${ }^{1}$ Department of Pediatrics, College of Medicine, Kyung Hee University, Seoul, ${ }^{2}$ Department of Pediatrics, Kyung Hee University Hospital at Gangdong, Seoul, Korea
}

Purpose: In Kawasaki disease (KD) patients, coronary artery complications, incomplete and refractory types occur more frequently in patients with streptococcal or other bacterial/viral infections. Recently, we observed a higher incidence of coronary lesions in KD patients with high anti-streptolysin 0 (ASO) titer. Therefore, we hypothesized that KD patients diagnosed with concurrent streptococcal infection have poor prognosis, with respect to treatment response and development of coronary artery lesions.

Methods: A retrospective review was performed in 723 patients with KD who were admitted to 2 major hospitals between June 2010 and September 2017.

Results: Among 723 patients with KD, 11 initially showed an elevated ASO titer (>320 IU/mL) or elevated follow-up ASO titer after treatment. Of these patients, 5 showed no response to the first intravenous immunoglobulin treatment, 3 had abnormalities of the coronary arteries. This is a significantly higher proportion of patients with a high ASO titer $(n=3,27.3 \%)$ than those with a normal ASO titer $(n=53$ [7.4\%], $P=0.047$ ). A severe clinical course was seen in $81.8 \%$ of patients in the high ASO group versus $14.5 \%$ of patients in the normal ASO group.

Conclusion: It is not certain whether acute streptococcal infection may cause KD, but this study revealed that KD with high ASO titers showed higher rates of severe clinical course. It may be helpful to analyze concurrent streptococcal infection in patients with a severe clinical course.

Key words: Antistreptolysin, Kawasaki disease, Coronary disease, Streptococcal infections

\section{Introduction}

Kawasaki disease $(\mathrm{KD})$ is an acute systemic inflammatory disease involving multiple organs and tissues. ${ }^{1)}$ Children $<5$ years old of age are most susceptible to $\mathrm{KD}{ }^{2)}$ The diagnosis of $\mathrm{KD}$ depends on the clinical manifestations according to the defined criteria of the presence of fever for at least 5 days, with at least 4 of the 5 following clinical features: (1) erythema and changes in the lips and oral mucosa, (2) bilateral nonexudative bulbar conjunctival injection, (3) polymorphous maculopapular rash (not petechial, bullous, or vesicular lesions), (4) changes in the extremities, including erythema and edema of the hands and feet in the acute phase and/or desquamation starting around the nail bed, and (5) cervical lymphadenopathy, usually unilateral (diameter $>1.5 \mathrm{~cm}$ ). ${ }^{2-4)}$ Incomplete $\mathrm{KD}$ is defined as prolonged unexplained fever without meeting at least three of the above five criteria. ${ }^{2)}$

Despite many investigations and many candidates, no unique infectious agents have been identified as the sole etiologic agent responsible for $\mathrm{KD}$. The role of viral infections in the pathogenesis of KD has been controversial. ${ }^{5-7)}$ The association with super antigens such as staphylococci or streptococci has been constantly argued. ${ }^{8-10)} \mathrm{In} \mathrm{KD}$, incomplete type of
Corresponding author: Kyung Lim Yoon, MD, PhD Department of Pediatrics, Kyung Hee University Hospital at Gangdong, 892 Dongnam-ro, Gangdong-gu, Seoul 05278, Korea

Tel: +82-2-440-6132

Fax: $+82-2-440-7175$

E-mail: ykr3215@hanmail.net https://orcid.org/0000-0003-4734-900X

Received: 31 August, 2018

Revised: 29 October, 2018

Accepted: 6 November, 2018

Copyright $@ 2019$ by The Korean Pediatric Society

This is an open-access article distributed under the terms of the Creative Commons Attribution NonCommercial License (http://creativecommons.org/ licenses/by-nc/4.0/n which permits unrestricted noncommercial use, distribution, and reproduction in any medium, provided the original work is properly cited. 
$\mathrm{KD}$ and coronary artery complications occur more frequently in patients with streptococcal or other bacterial/viral infections. ${ }^{11-13)}$ Some reports have stated that systemic inflammation is linked to acute coronary events, including endothelial dysfunction. ${ }^{14,15}$ We hypothesized that KD patients diagnosed with streptococcal infection have poor prognoses, especially in terms of treatment response and the development of coronary artery lesions.

Here, we investigated the coronary artery lesions and response to intravenous immunoglobulin (IVIG) in relation to the level of antistreptolysin 0 (ASO) in patients with KD.

\section{Materials and methods}

\section{Study participants}

We retrospectively reviewed KD patients admitted to Kyung Hee University Medical Center and Kyung Hee University Hospital at Gangdong between June 2010 and September 2017. The clinical data of a total $723 \mathrm{KD}$ patients were reviewed. Only patients for whom ASO titer and echocardiography data were available were included in the study. The Institutional Review Board of Kyung Hee University Hospital at Gangdong approved this study (approval number: 2018-08-047) and waived the need for written informed consent.

\section{Laboratory data and echocardiography}

Laboratory data including microbiology results, imaging studies, and echocardiography examinations were collected and reviewed. A standardized set of laboratory tests was performed before and 36 hours after the end of IVIG infusion, including complete blood count, white blood cell differential count, erythrocyte sedimentation rate, C-reactive protein, albumin, alanine aminotransferase, aspartate aminotransferase, bilirubin, creatinine, ASO, and urine analysis. All except one patient diagnosed with $\mathrm{KD}$ received IVIG ( $\mathrm{g} / \mathrm{kg}$ ) for 12 hours and these blood tests were performed 36 hours after the end of treatment. Only 1 patient did not receive IVIG, because he was referred to our hospital without a fever. Blood culture, throat swab, respiratory viral polymerase chain reaction (PCR), and serum Mycoplasma antibody tests were performed in patients who were suspected of having an infection. Respiratory viral PCR can detect 12 respiratory viruses and subtypes included the following: adenovirus, respiratory syncytial viruses $A$ and $B$, influenza viruses $A$ and B, parainfluenza 1, 2 and 3, rhinovirus, metapneumovirus, and coronaviruses 229E, NL63, OC43, and HKU1. Serial echocardiography exams were performed during hospitalization by an expert pediatric cardiologist. By correcting for BSA, a $z$ score system provided by Kobayashi et al. ${ }^{16)}$ was used in our study. In this study, $z$ score $\geq 2.5$ was regarded as a coronary artery abnormality.

\section{Diagnostic criteria}

The diagnosis of KD depends on the clinical manifestations according to the defined criteria of the presence of fever for at least 5 days, with at least 4 of the 5 principal clinical features. ${ }^{2)}$ Incomplete $\mathrm{KD}$ is defined as prolonged unexplained fever without meeting at least three of the 5 criteria. $^{2)}$

We enrolled patients if their ASO titer had increased 4 fold in 2 measurements. ${ }^{177}$ This is generally accepted as significant in clinical practice. However, if the ASO titer could be measured only once, we enrolled $>320 \mathrm{IU} / \mathrm{mL}$, which is the upper normal limit presented in a recent study and many other studies. ${ }^{18-20)}$ If the peak ASO titer was $<320 \mathrm{IU} / \mathrm{mL}$ in a patient who was measured twice, the patient was excluded from the study group. Patients who were discharged or transferred without appropriate treatment were also excluded.

A good clinical course group is defined as fever subsiding within 36 hours after the end of first IVIG treatment without any coronary artery abnormalities. On the other hand, relatively severe $\mathrm{KD}$ groups were defined as follows; (1) no response to the first IVIG treatment, and a second IVIG treatment or methylprednisolone (MPD) pulse therapy were required, or (2) KD patients with coronary artery abnormalities.

\section{Statistical analysis}

Fisher exact test was used to compare data using IBM SPSS Statistics ver. 20.0 (IBM Co., Armonk, NY, USA), and values of $P<0.05$ were considered statistically significant.

\section{Results}

A total of 723 patients were diagnosed with KD between June 2010 and September 2017. Patients were admitted to the hospital on average 5.9 days after the onset of fever. These patients' clinical data are summarized in Table 1. Of them, 9 (81.8\%) had a severe clinical course. Only 2 patients (18.2\%) had a relatively good clinical course.

Of the $11 \mathrm{KD}$ patients with elevated ASO levels, 5 were boys and 4 were girls (ratio, 0.83:1), with a mean age of 65.5 months (range, 10-131 months) at the time of the KD diagnosis. Ten patients had complete KD, while 1 had incomplete KD. One of the patients (female, 73 months) experienced a KD relapse 15 days after the first treatment.

At the time of diagnosis, all 11 patients had a fever, (mean duration, 9.2 days; range, 5-21 days) and a nonexudative eye injection. 10 patients (90.9\%) had a polymorphous rash, 9 patients (81.8\%) displayed noticeable changes in the lips or oral mucosa, 8 patients (72.7\%) had erythema and edema of the extremities, and 7 patients (63.6\%) had cervical lymphadenopathy. The mean fever duration was 9.4 days in the severe $\mathrm{KD}$ group and 8 days in the good clinical course group. All patients in the good clinical course group had complete KD, fevers that subsided within 36 hours after the first IVIG treatment, and normal coronary arteries. At the time of diagnosis, 
Table 1. Clinical and laboratory data of the 11 patients with Kawasaki disease and a high ASO titer

\begin{tabular}{|c|c|c|c|c|c|c|c|c|c|c|c|c|c|c|c|}
\hline No. & Sex & $\begin{array}{l}\text { Age } \\
\text { (mo) }\end{array}$ & $\mathrm{F}$ & $\mathrm{Ei}$ & $L$ & $\mathrm{R}$ & $E$ & LN & Type & $\begin{array}{c}\text { BNP } \\
(\mathrm{pg} / \mathrm{mL})\end{array}$ & $\begin{array}{c}\text { Echo } \\
\text { z scores }\end{array}$ & $\begin{array}{c}\text { ASO } \\
\text { (initial/peak) }\end{array}$ & $\begin{array}{c}\text { IVIG } \\
\text { MPD pulse }\end{array}$ & Associated pathogen & $\begin{array}{l}\text { Antibiotics } \\
\text { administered }\end{array}$ \\
\hline 1 & $\mathrm{~F}$ & 100 & 10 & + & - & - & - & + & Incomplete & 569.6 & 1.85 & $274 / 773$ & 2 & & \\
\hline 2 & $\mathrm{~F}$ & 73 & $7+5^{\dagger}$ & + & + & + & + & + & Complete & 328.0 & 2.37 & $55 / 487$ & 2 & & Cefotaxime \\
\hline 3 & M & 55 & 21 & + & + & + & + & - & Complete & - & 3.91 & 506 & 0 & Influenza B & Oseltamivir \\
\hline 4 & $F$ & 42 & 9 & + & + & + & + & + & Complete & 381.0 & 2.28 & $35.3 / 514$ & 2 & & \\
\hline 5 & $\mathrm{~F}$ & 52 & 7 & + & + & + & + & - & Complete & 191.5 & -0.7 & $594 / 1,020$ & 2 & & \\
\hline 6 & M & 63 & 9 & + & + & + & + & - & Complete & 140.0 & 0.65 & $1,023 / 2,611$ & 1 & & Augmentin \\
\hline 7 & M & 49 & 6 & + & + & + & + & + & Complete & 1235.0 & 2.5 & $971 / 1,957$ & 1 & & \\
\hline 8 & $\mathrm{~F}$ & 10 & 10 & + & - & + & + & + & Complete & 67.0 & 0.4 & 7/348 & 2 & Rhino virus & Augmentin \\
\hline 9 & M & 131 & 10 & + & + & + & - & + & Complete & 66.0 & 3.52 & $267 / 714$ & 1 & & $\begin{array}{l}\text { Cefotaxime } \\
\text { Augmentin }\end{array}$ \\
\hline $10^{*}$ & $\mathrm{~F}$ & 58 & 9 & + & + & + & + & + & Complete & 43.0 & 0.36 & $52 / 430$ & 1 & Mycoplasma pneumoniae & Clarithromycin \\
\hline $11^{*}$ & M & 87 & 7 & + & + & + & - & + & Complete & 524.0 & 0.56 & 556 & 1 & Mycoplasma pneumoniae & Clarithromycin \\
\hline
\end{tabular}

ASO titers were determined before and after IVIG treatment.

ASO, antistreptolysin $0 ; \mathrm{F}$, fever days; Ei, nonexudative eye injection; $L$, changes in the lips or oral mucosa; R, polymorphous rash; $E$, erythema and edema of the extremities; LN, cervical lymphadenopathy; BNP, brain natriuretic peptide; IVIG, intravenous immunoglobulin; MPD, methylprednisolone; Augmentin, amoxicillin/ clavulanic acid.

*Patients 10 and 11 had a relatively good clinical course in which the fever subsided within 36 hours after the first IVIG treatment. On the other hand, patients $1-9$ had a worse clinical course in which the fever persisted for $>36$ hours after the first IVIG treatment. ${ }^{\dagger}$ Patient No. 2 experienced Kawasaki disease relapse 15 days after the first IVIG administration.

Table 2. Comparisons of clinical outcomes of patients with Kawasaki disease having a high versus normal ASO titer

\begin{tabular}{lcccr}
\hline Variable & $\begin{array}{c}\text { Total } \\
(\mathrm{n}=723)\end{array}$ & $\begin{array}{c}\text { Elevated ASO } \\
(\mathrm{n}=11)\end{array}$ & $\begin{array}{c}\text { Normal ASO } \\
(\mathrm{n}=712)\end{array}$ & P value \\
\hline Coronary artery lesion & $56(6.9)$ & $3(27.3)$ & $53(7.4)$ & $\mathbf{0 . 0 4 7}$ \\
Initial IVIG nonresponse & $75(10.4)$ & $5(45.5)$ & $70(9.8)$ & $\mathbf{0 . 0 0 3}$ \\
Severe clinical course & $112(15.5)$ & $9(81.8)$ & $103(14.5)$ & $<0.001$
\end{tabular}

Values are presented as number of patients (\%).

ASO, antistreptolysin 0; IVIG, intravenous immunoglobulin.

Boldface indicates a statistically significant difference with $P<0.05$.

4 patients (36.4\%) had a confirmed concurrent infection, the most common pathogens being Mycoplasma pneumoniae $(\mathrm{n}=2)$, rhinovirus $(n=1)$, and influenza $B(n=1)$, confirmed by respiratory viral PCR. Only 1 patient was confirmed to have Streptococcus pyogenes, by a throat culture at diagnosis. Blood cultures were all negative in these 11 patients.

Four patients with a high ASO titer did not receive any antibiotics despite a sustained fever, whereas the other 7 did receive antibiotics. However, the prevalence of coronary artery lesions did not differ between them.

As for seasonal patterns, 4 cases were diagnosed in early summer ( 2 in May, 1 in June, and 1 in July), while 3 were diagnosed in winter (1 in January, 2 in February). No cases were diagnosed in the fall.

Table 2 shows the numbers and percentages of patients by group. Those with a severe clinical course developed coronary lesions, received a second round of IVIG, or required MPD pulse therapy. A severe clinical course was seen in $81.8 \%$ of patients in the high ASO group versus 14.5\% of patients in the normal ASO group.

Cardiac involvement was screened for in all patients using echo- cardiography. A significantly higher proportion of patients with a high ASO titer ( $\mathrm{n}=3,27.3 \%)$ than those with a normal ASO titer ( $\mathrm{n}=$ $53 ; 7.4 \%)$ showed abnormalities of the coronary arteries $(P=0.047)$. A second round of IVIG was administered in more patients with an elevated ASO titer (45.5\%) than patients in the normal ASO group $(9.8 \%)$.

\section{Discussion}

Here we reported the severity of $\mathrm{KD}$ with streptococcal infections among $723 \mathrm{KD}$ patients. Among them, 11 had elevated ASO levels before or after IVIG treatment. Of those, 9 had high ASO titers or 4-fold increased titers, and clinical findings for them were worse than those for the other KD patient. Five patients showed no response to the first IVIG treatment (45.5\%, $P=0.003$ ), 3 had abnormalities of the coronary arteries (27.3\%, $P=0.047)$. A severe clinical course was seen in $81.8 \%$ of patients in the high ASO group versus $14.5 \%$ of patients in the normal ASO group $(P<0.001)$.

Jordan-Villegas et al. ${ }^{11)}$ reported that patients with $\mathrm{KD}$ who also had respiratory viruses have a higher frequency of coronary artery dilatation and were more often diagnosed with incomplete KD. Other researchers have linked streptococcal infection and $\mathrm{KD}{ }^{21,22)}$ In particular, the reason might be clinical overlap between streptococcal infection and $\mathrm{KD}$, such as persistent fever, a desquamative rash, and erythema of the mucous membranes in streptococcal toxic shock syndrome. A superantigen-mediated process might be related to this process. ${ }^{8)}$ Matsubara and Fukaya ${ }^{8)}$ suggest that $\mathrm{KD}$ is a response to superantigens in genetically susceptible individuals. 
These all support our results that $\mathrm{KD}$ with streptococcal infection had a severe clinical course.

In temperate climates, the incidence of group A streptococcal infection peaks during the winter and early spring. In Japan, several group A streptococcal serotypes showed a bimodal distribution, with peaks in December to February and again in May to June and a prominent nadir of infections in September. ${ }^{23)}$ In Korea, a seasonal pattern was observed in which KD occurred more often in early summer (May, June, and July) and winter (January and February), and occurred less often in the spring and fall. ${ }^{24)} 0$ the $11 \mathrm{KD}$ diagnoses, 4 were made in early summer ( 2 in May, 1 in June, and 1 in July), and 3 were made in winter (1 in January, 2 in February). No patients were diagnosed in the fall. This may imply that infectious agents might be the trigger of $\mathrm{KD}$ and that Streptococcus is one of the possible agents is the possible agents.

Measurement of ASO is relatively inexpensive and easy to perform because the proceeds, along with other blood tests. However, there are significant difficulties assigning a "normal" ASO titer value. The only upper normal limit is $>320 \mathrm{IU} / \mathrm{mL}$, presented in a recent study and many other studies. ${ }^{20)}$ Also, ASO titer does not always indicate a recent streptococcal infection. Therefore, an increase in an ASO titer is indicative of a preceding group A Streptococcus infection, so sequential measurements are recommended. ${ }^{17-19)} \mathrm{We}$ attempted to obtain 2 sequential measurements, but only a single measurement was performed in some patients. IVIG contains the pooled immunoglobulins from the plasma of approximately a thousand or more blood donors. As a cocktail of different antibodies against various virulence factors including Streptococcus, it can be provided to the patients. In this study, among 11 patients, 5 patients' ASO titer was high (range, 506-1,023) at the time of diagnosis, and 6 patients' ASO titer elevated after IVIG treatment.

In our study, 4 of the 11 patients with a high ASO titer did not receive any antibiotics despite a sustained fever, whereas the other 7 did receive antibiotics. However, the prevalence of coronary artery lesions did not differ between them. In 2018, Han and Lee ${ }^{25)}$ report the anbibiotics used in $140 \mathrm{KD}$ patients. The $\mathrm{KD}$ patients with antibiotics experienced more hospital days $(P=0.045)$. On the other hand, there was no difference in unresponsiveness to IVIG and development of coronary abnormalities between the 2 groups.

Despite its many limitations, our study's main strength is that we treated all patients using a relatively constant protocol. A series of blood tests was performed at the time of diagnosis, including the ASO titer, because the tests are simple and do not require additional specimens. IVIG $2 \mathrm{~g} / \mathrm{kg}$ was administered slowly over 12 hours as soon as KD was diagnosed and discontinued whenever a patient's temperature exceeded $38^{\circ} \mathrm{C}$. Thirty-six hours after the end of the IVIG administration, the blood tests, including the ASO titer, were repeated to exclude acute streptococcal infection and the fever pattern was closely observed. In addition, echocardiography was performed by an expert pediatric cardiologist at the admission, 2-3 weeks later, 2 months later, or 1 year later depending on each patient's status to monitor for coronary artery or other transient lesions.

In this study, we do not know whether acute streptococcal infection or past infection caused the KD. However, in KD with acute streptococcal infection, the fever duration was longer than average and the frequency of coronary artery aneurysms was higher. In cases of incomplete $\mathrm{KD}$ or prolonged fever, it may be necessary to diagnose acute streptococcal infection using ASO titer or culture; therefore, more aggressive therapy is needed to prevent coronary artery lesions. Prospective studies with larger samples are needed to further examine the relationship between $\mathrm{KD}$ with coronary lesions and elevated ASO titers.

\section{Conflicts of interest}

No potential conflict of interest relevant to this article was reported.

\section{References}

1. Amano S, Hazama F, Kubagawa H, Tasaka K, Haebara H, Hamashima Y. General pathology of Kawasaki disease. On the morphological alterations corresponding to the clinical manifestations. Acta Pathol Jpn 1980;30:681-94.

2. McCrindle BW, Rowley AH, Newburger JW, Burns JC, Bolger AF, Gewitz M, et al. Diagnosis, treatment, and long-term management of kawasaki disease: a scientific statement for health professionals from the American Heart Association. Circulation 2017;135:e927-99.

3. Newburger JW, Takahashi M, Gerber MA, Gewitz MH, Tani LY, Burns JC, et al. Diagnosis, treatment, and long-term management of Kawasaki disease: a statement for health professionals from the Committee on Rheumatic Fever, Endocarditis and Kawasaki Disease, Council on Cardiovascular Disease in the Young, American Heart Association. Circulation 2004;110:2747-71.

4. Council on Cardiovascular Disease in the Young; Committee on Rheumatic Fever, Endocarditis, and Kawasaki Disease; American Heart Association. Diagnostic guidelines for Kawasaki disease. Circulation 2001;103:335-6.

5. Lloyd AJ, Walker C, Wilkinso M. Kawasaki disease: is it caused by an infectious agent? Br J Biomed Sci 2001;58:122-8.

6. Rowley AH, Baker SC, Shulman ST, Rand KH, Tretiakova MS, Perlman EJ, et al. Ultrastructural, immunofluorescence, and RNA evidence support the hypothesis of a "new" virus associated with Kawasaki disease. J Infect Dis 2011;203:1021-30.

7. Benseler SM, McCrindle BW, Silverman ED, Tyrrell PN, Wong J, Yeung RS. Infections and Kawasaki disease: implications for coronary artery outcome. Pediatrics 2005;116:e760-6.

8. Matsubara K, Fukaya T. The role of superantigens of group A Streptococcus and Staphylococcus aureus in Kawasaki disease. Curr Opin Infect Dis 2007;20:298-303.

9. Meissner HC, Leung DY. Superantigens, conventional antigens and the etiology of Kawasaki syndrome. Pediatr Infect Dis J 2000;19:91-4.

10. Rowley AH. The etiology of Kawasaki disease: superantigen or conventional antigen? Pediatr Infect Dis J 1999;18:69-70.

11. Jordan-Villegas A, Chang ML, Ramilo 0, Mejías A. Concomitant 
respiratory viral infections in children with Kawasaki disease. Pediatr Infect Dis J 2010;29:770-2.

12. Lo JY, Minich LL, Tani LY, Wilkes J, Ding Q, Menon SC. Factors associated with resource utilization and coronary artery dilation in refractory Kawasaki disease (from the Pediatric Health Information System Database). Am J Cardiol 2016;118:1636-40.

13. Kitano N, Suzuki H, Takeuchi T, Suenaga T, Kakimoto N, Shibuta S, et al. Epidemiologic features and prognostic factors of coronary artery lesions associated with Kawasaki disease based on a 13-year cohort of consecutive cases identified by complete enumeration surveys in Wakayama, Japan. J Epidemiol 2014;24:427-34.

14. Hingorani AD, Cross J, Kharbanda RK, Mullen MJ, Bhagat K, Taylor $\mathrm{M}$, et al. Acute systemic inflammation impairs endothelium-dependent dilatation in humans. Circulation 2000;102:994-9.

15. Binak E, Gunduz H, Binak D, Yilmaz F. Association between recent group A beta-hemolytic. Internet J Cardiol 2006;4:1-5.

16. Kobayashi T, Fuse S, Sakamoto N, Mikami M, Ogawa S, Hamaoka K, et al. A new $\mathrm{Z}$ score curve of the coronary arterial internal diameter using the Lambda-Mu-Sigma method in a pediatric population. J Am Soc Echocardiogr 2016;29:794-801.

17. Steer AC, Smeesters PR, Curtis N. Streptococcal serology: secrets for the specialist. Pediatr Infect Dis J 2015;34:1250-2.
18. Shet A, Kaplan EL. Clinical use and interpretation of group A streptococcal antibody tests: a practical approach for the pediatrician or primary care physician. Pediatr Infect Dis J 2002;21:420-6.

19. Sen ES, Ramanan AV. How to use antistreptolysin 0 titre. Arch Dis Child Educ Pract Ed 2014;99:231-8.

20. Machado CS, Ortiz K, Martins Ade L, Martins RS, Machado NC. Antistreptolysin 0 titer profile in acute rheumatic fever diagnosis. J Pediatr (Rio J) 2001;77:105-11.

21. Cox F, Foshee W, Miller J Jr, Moore S. Simultaneous Kawasaki disease and group A streptococcal pharyngitis. Clin Pediatr (Phila) 1993;32: 48-50.

22. Hoare S, Abinun M, Cant AJ. Overlap between Kawasaki disease and group A streptococcal infection. Pediatr Infect Dis J 1997;16:633-4.

23. Burns JC, Cayan DR, Tong G, Bainto EV, Turner CL, Shike H, et al. Seasonality and temporal clustering of Kawasaki syndrome. Epidemiology 2005;16:220-5.

24. Ha S, Seo GH, Kim KY, Kim DS. Epidemiologic study on Kawasaki disease in Korea, 2007-2014: based on Health Insurance Review Ct Assessment Service Claims. J Korean Med Sci 2016;31:1445-9.

25. Han SB, Lee SY. Antibiotic use in children with Kawasaki disease. World J Pediatr 2018;14:621-2. 